\title{
Intellectual, educational, and behavioural sequelae after cranial irradiation and chemotherapy
}

\author{
Vicki Anderson, Elizabeth Smibert, Henry Ekert, Tim Godber
}

\begin{abstract}
Cognitive and educational sequelae are inconsistently reported in children treated with cranial irradiation for acute lymphoblastic leukaemia. This study investigated differences in these skills after cranial irradiation, controlling the effects of chemotherapy and psychosocial factors. Three groups were evaluated: 100 children diagnosed with acute lymphoblastic leukaemia and treated with cranial irradiation and chemotherapy; 50 children diagnosed with acute lymphoblastic leukaemia or other cancers and treated with chemotherapy alone; and a healthy control group of 100 children. Children in the clinical groups stopped treatment at least two years before evaluation and had no history of relapse. Children were aged between 7 and 16 at the time of assessment. Evaluation included cognitive, educational, and behavioural measures.

Analyses found that children receiving cranial irradiation and chemotherapy performed more poorly than non-irradiated groups on intellectual and educational tests, with verbal and attentional deficits most pronounced. Children receiving chemotherapy alone performed similarly to controls, suggesting such treatment is not associated with adverse neurobehavioural sequelae.

(Arch Dis Child 1994; 70: 476-483)
\end{abstract}

Before 1970, children diagnosed with acute lymphoblastic leukaemia had a life expectancy of less than one year. Death often resulted, not from the original disease of the blood, but from progression of the disease within the central nervous system. ${ }^{1}$ Administration of cranial irradiation therapy, in conjunction with intrathecal methotrexate, has dramatically improved the life expectancy of these children. ${ }^{2}$ Now $70 \%$ can expect long term survival and possible cure. ${ }^{3}$

Although such treatment programmes have clearly resulted in prolonged disease-free survival for children experiencing acute lymphoblastic leukaemia, associated and adverse long term central nervous system sequelae have been reported, particularly where treatment regimens include cranial irradiation. Histological and radiographic studies have revealed two forms of delayed neuropathology after cranial irradiation; leukoencephalopathy and mineralising microangiopathy. These are not usually apparent until several months after cranial irradiation and are characterised by damage to areas surrounding the basal ganglia, including myelin degeneration, ventricular dilatation, and cerebral calcifications. ${ }^{4-6}$ Symptoms associated with these problems include seizures, ataxia, and slurred speech and occur most often after high doses of cranial irradiation. ${ }^{7}$ Although the neurological effects of chemotherapeutic agents, particularly methotrexate, are less well documented, a review ${ }^{8}$ has suggested that damage has been observed in the white matter after chemotherapy, with the mechanism being similar to that described after cranial irradiation and including vascular and glial injury. ${ }^{9}$

A number of studies have addressed the psychological and educational consequences of treatment for acute lymphoblastic leukaemia. Although most studies document few deficits in these skill areas after chemotherapy, ${ }^{10}$ even in high doses, ${ }^{11}$ the findings for children treated with cranial irradiation and chemotherapy are less consistent. Some workers report significant deficits in children treated with cranial irradiation, ${ }^{12-14}$ whereas others find the performances of these children to be similar to those of non-irradiated groups. ${ }^{15} 16$ Research which has identified deficits after cranial irradiation indicates that problems are often in the areas of non-verbal activities, such as fine motor coordination, visuospatial ability, and somatosensory functioning ${ }^{1718}$ as well as in information processing abilities such as attention and new learning. ${ }^{19-20}$ Educational deficits are also described, with arithmetic difficulties most often reported. ${ }^{21}$

A handful of workers have focused on the relationship between neuropathological abnormalities and cognitive outcome in an attempt to determine the organic basis of the observed psychological sequelae. In general, findings have indicated some association between the type and severity of brain abnormality, as seen by computed tomography, and patterns of neuropsychological dysfunction. ${ }^{22} 23$ In these studies central nervous system anomalies are most commonly described in the region of the basal ganglia, particularly the caudate, which has extensive neural connections to the frontal lobes. Children treated with cranial irradiation and exhibiting cerebral calcifications in these areas have been found to exhibit attentional and linguistic deficiencies specifically. Such neuropsychological deficits have also been noted in other neurological disorders which involve disruptions to these cerebral regions (for example, multiple sclerosis). ${ }^{24}$ 
Critical evaluation of research addressing the specific consequences of cranial irradiation suggests numerous methodological flaws, including small sample size, bias in sample selection, use of inappropriate comparison groups, and failure to differentiate between the possible sequelae of cranial irradiation and chemotherapy. Further, variations in the treatment protocols across individual centres are rarely addressed, with many samples heterogeneous in terms of sequence of treatments and dose of cranial irradiation.

Recent research indicates that such variations may be critical to outcome, with lower doses of cranial irradiation and preirradiation treatment with methotrexate both noted to lead to a better outcome. ${ }^{25-28}$ These design problems clearly limit the conclusions that can be drawn from such studies. It is worthy of note that even recent reviews differ in their interpretations and conclusions about cognitive and educational sequelae after cranial irradiation. 22-31

The lack of consistency of these findings has encouraged an interpretation which argues that psychosocial factors may be central to the existence of cognitive and educational problems in children treated with cranial irradiation. Indeed, a diagnosis of leukaemia inevitably leads to a series of life stresses including admission to hospital, disruption to family functioning, adaptation to diagnosis of life threatening illness, prolonged and unpleasant medical treatment often associated with severe side effects (for example loss of hair, nausea, fatigue), absence from school, and social isolation. It is not surprising that these children have been observed to show excessive anxiety, ${ }^{32-34}$ depression, ${ }^{35}$ poor self concept, ${ }^{36}$ and immature social skills, ${ }^{37-39}$ The relation between these emotional and social problems and intellectual and educational functioning is less clear. Eiser points out that regular absences from school due to medical treatment may cause children to miss essential lessons and so be continually behind in their work, resulting in poor school performance. ${ }^{40}$ Evidence from published work addressing chronic illness in children supports this claim. ${ }^{41}$ Intellectual deficits are less easily explained by such psychosocial factors however.

Few studies have attempted to control psychosocial factors when comparing the educational and intellectual functioning of children treated with cranial irradiation with other groups. The inclusion of a group of children diagnosed with cancer and treated with chemotherapy alone provides an opportunity to control such confounding variables. These children have also been diagnosed with a life threatening disease, which involves a similar treatment regimen. They too have frequent absences from school and may miss essential lessons. The inclusion of such a comparison group allows a more accurate analysis of the relative contribution of psychosocial and neuropsychological parameters to the educational and intellectual functioning of children after cranial irradiation.
The present study was undertaken to investigate the long term intellectual and educational sequelae of children treated with cranial irradiation. The study design aims to overcome a number of methodological difficulties inherent in previous research. Firstly, as the Royal Children's Hospital, Melbourne treats the majority of children in the state of Victoria who are diagnosed with acute lymphoblastic leukaemia, the available clinical sample is relatively large and representative of the acute lymphoblastic leukaemia population. Secondly, the specific effects of cranial irradiation will be isolated from the possible effects of chemotherapy by using two cancer groups, one treated with cranial irradiation and chemotherapy and a second treated with chemotherapy alone. The inclusion of a 'chemotherapy only' group provides consistency across clinical groups with respect to the experience of life threatening illness, missed schooling, and associated family trauma, and minimises the possible confounding effects of emotional and psychosocial factors on educational and intellectual abilities. Further, comparison with a healthy control group enables investigation of the specific nature and degree of intellectual and educational disabilities which may occur as a consequence of cranial irradiation and chemotherapy.

\section{Subjects and methods \\ SUBJECTS}

The sample consisted of three groups of children: group 1, 100 survivors of acute lymphoblastic leukaemia, who had been treated with chemotherapy and cranial irradiation; group 2, 50 survivors of acute myeloid leukaemia, acute lymphoblastic leukaemia, or solid tumour (no central nervous system disease) who had been treated with chemotherapy alone; and group 3, 100 healthy control children chosen from local schools and matched with groups 1 and 2 according to age, sex, and socioeconomic status.

Children treated for acute lymphoblastic leukaemia at the Royal Children's Hospital, Melbourne between 1977 and 1987 according to the ANZCCSG study (III), study (IV), or study (V) protocols, ${ }^{42}$ were considered for inclusion in group 1.

Within each of these treatment protocols cranial irradiation was given to children over 2 years of age after remission had been recorded after induction chemotherapy. Each child received a course of cranial irradiation of either 24 or $18 \mathrm{~Gy}$ given with four doses at weekly intervals of intrathecal methotrexate as part of prophylaxis against central nervous system leukaemia. Before irradiation the children had received two doses of intrathecal methotrexate given on day 1 and day 21 of the chemotherapy regimen in study IV and study V, but in study III no preirradiation intrathecal methotrexate was given.

Group 2, comprising children treated with chemotherapy alone, included 24 children who were treated with intrathecal methotrexate and 26 who had no intrathecal chemotherapy. The 
Table 1 Demographic characteristics of three comparison groups

\begin{tabular}{llllll}
\hline & $\begin{array}{l}\text { No } \\
\text { of } \\
\text { boys }\end{array}$ & $\begin{array}{l}\text { Mean (SD) } \\
\text { age at } \\
\text { evaluation }\end{array}$ & $\begin{array}{l}\text { Mean (SD) } \\
\text { age at } \\
\text { diagnosis }\end{array}$ & $\begin{array}{l}\text { Mean (SD) } \\
\text { time since } \\
\text { treatment }\end{array}$ & $\begin{array}{l}\text { Mean }(S D) \\
\text { SES } \\
\text { score }\end{array}$ \\
\hline $\begin{array}{l}\text { Group 1 (CRT+chemotherapy) } \\
(\mathrm{n}=100)\end{array}$ & 45 & $12 \cdot 1(2 \cdot 8)$ & $4.5(2 \cdot 6)$ & $5 \cdot 0(2 \cdot 6)$ & $4 \cdot 6(1 \cdot 1)$ \\
$\begin{array}{l}\text { Group 2 (chemotherapy only) } \\
(\mathrm{n}=50)\end{array}$ & 24 & $11 \cdot 7(2 \cdot 9)$ & $5 \cdot 0(2 \cdot 6)$ & $4 \cdot 5(2 \cdot 9)$ & $4 \cdot 2(1 \cdot 2)$ \\
$\begin{array}{l}\text { Group 3 (healthy controls) } \\
(\mathrm{n}=100)\end{array}$ & 48 & $12 \cdot 0(2 \cdot 7)$ & - & - & $4 \cdot 4(1 \cdot 3)$ \\
\hline
\end{tabular}

CRT $=$ cranial irradiation

^Daniel's Scale of Occupational Prestige ${ }^{61}$ using father's occupation.

children receiving intrathecal methotrexate were treated on the study $\mathrm{V}$ protocol but with irradiation omitted from the treatment regimen. They received intrathecal methotrexate in an age related dose on day 1 and day 21 of induction chemotherapy, then weekly for four weeks, as did the irradiation children, and then once every eight weeks until the completion of chemotherapy, two years after the initial recorded remission.

Criteria for inclusion for the two clinical groups were: (a) end of treatment at least two years before assessment, to minimise the likelihood of ongoing central nervous system recovery in the sample; (b) continuous complete remission since the initial diagnosis; (c) no history of neurological developmental, or psychiatric disorder before diagnosis of acute lymphoblastic leukaemia; (d) no central nervous system disease present at diagnosis; and (e) chronological age between 7 and 16 years at time of evaluation to enable administration of consistent test protocols for all children.

For groups 1 and 2, children meeting these criteria were contacted by letter and asked to participate in the study. For group 1, the first 100 children and families consenting to participate in the study were included. For group 2, the first 50 children and families agreeing to participate in the study were enroled in the study.

Group 3, the healthy control group, was recruited from schools within the Melbourne metropolitan area. Two primary and two secondary schools were randomly chosen from the 10th, 30th, 50th, 70th, and 90th

Table 2 Mean (SD) WISC-R subtest scaled scores and IQ scores for the three comparison groups

\begin{tabular}{|c|c|c|c|}
\hline Subtest & $\begin{array}{l}\text { Group } 1 \\
(C R T+\text { chemotherapy) } \\
(n=100)\end{array}$ & $\begin{array}{l}\text { Group } 2 \\
\text { (chemotherapy only) } \\
(n=50)\end{array}$ & $\begin{array}{l}\text { Group } 3 \\
\text { (healthy controls) } \\
(n=100)\end{array}$ \\
\hline 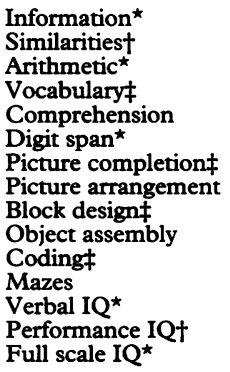 & $\begin{array}{c}8 \cdot 9(2 \cdot 6) \\
8 \cdot 7(2 \cdot 9) \\
8 \cdot 7(3 \cdot 0) \\
8 \cdot 7(2 \cdot 9) \\
9 \cdot 5(2 \cdot 7) \\
7 \cdot 2(2 \cdot 4) \\
9 \cdot 6(2 \cdot 2) \\
9 \cdot 3(2 \cdot 9) \\
10 \cdot 5(3 \cdot 1) \\
10 \cdot 2(2 \cdot 9) \\
9 \cdot 4(2 \cdot 9) \\
10 \cdot 9(3 \cdot 0) \\
92 \cdot 9(14 \cdot 0) \\
98 \cdot 2(12 \cdot 6) \\
94 \cdot 9(13 \cdot 1)\end{array}$ & $\begin{array}{c}10 \cdot 5(2 \cdot 3) \\
9 \cdot 9(2 \cdot 9) \\
10 \cdot 6(2 \cdot 2) \\
9 \cdot 6(2 \cdot 8) \\
9 \cdot 8(2 \cdot 6) \\
8 \cdot 3(2 \cdot 8) \\
10 \cdot 2(2 \cdot 7) \\
9 \cdot 6(2 \cdot 7) \\
11 \cdot 7(3 \cdot 1) \\
11 \cdot 0(2 \cdot 8) \\
10 \cdot 2(2 \cdot 7) \\
11 \cdot 9(3 \cdot 2) \\
100 \cdot 1(13 \cdot 1) \\
104 \cdot 1(13 \cdot 7) \\
102 \cdot 3(13.5)\end{array}$ & $\begin{array}{c}10 \cdot 6(2 \cdot 6) \\
10 \cdot 2(2 \cdot 9) \\
10 \cdot 1(2 \cdot 5) \\
9 \cdot 7(2 \cdot 4) \\
9.9(2 \cdot 8) \\
8 \cdot 8(3 \cdot 1) \\
10.4(2 \cdot 7) \\
9 \cdot 8(2 \cdot 3) \\
11.5(2 \cdot 9) \\
10 \cdot 6(2 \cdot 7) \\
10 \cdot 4(2 \cdot 7) \\
10.9(3 \cdot 2) \\
100 \cdot 2(12 \cdot 5) \\
103 \cdot 1(12 \cdot 2) \\
101.7(12 \cdot 3)\end{array}$ \\
\hline
\end{tabular}

CRT $=$ cranial irradiation.

${ }^{\star} \mathrm{p}<0.001 ; \mathrm{tp}<0.01 ; \neq<0.05$. socioeconomic centile levels according to census information on the school catchment areas. Letters of participation were sent to one primary and one secondary school from each centile level. One grade was randomly selected from each age level (year 2 to year 11) at each school. Letters giving detailed information about the study were then sent to two boys and two girls randomly selected from the identified grade, with one boy and one girl being included in the study. Identified children with a history of neurological, developmental, or psychiatric disorders were excluded from participation. Only children resident in Australia for at least five years were included, to control for ethnicity across groups.

Table 1 gives the demographic characteristics of the sample.

\section{MEASURES}

The evaluation measures were chosen to focus on intellectual, educational, and behavioural functioning. Intellectual abilities were measured using the 12 subtests from the Wechsler Intelligence Scale for Children Revised (WISC-R). ${ }^{43}$ Verbal, performance, and full scale intellectual quotients (mean 100, SD 15) were calculated and scaled scores (mean 10, SD 3) for each of the 12 subtests were used in statistical analyses of intellectual functioning. The reading, spelling, and arithmetic subtests of the Wide Range Achievement Test - Revised (WRAT-R) ${ }^{44}$ were administered to determine educational abilities and standard scores (mean 100, SD 10) were used in analyses. Behavioural characteristics were assessed for the two clinical groups using the Child Behaviour Checklist, ${ }^{45}$ a standardised parent rated measure of social competence and behavioural status. This measure provides social competence and behaviour problem scores expressed as $\mathrm{T}$ scores (mean 50, SD 10), as well as a series of subscale scores and problem behaviour syndromes which address specific aspects of social competency and behavioural patterns.

\section{PROCEDURE}

All families were initially contacted by letter with an invitation to participate in the study. Those agreeing were evaluated at an outpatient psychology clinic (groups 1 or 2) or at their school (group 3). Evaluation took place over two sessions held on the same day. Within these sessions the order of administration of tasks was fixed.

\section{STATISTICAL ANALYSIS}

Statistical analysis addressed a number of issues. Firstly, the three groups were compared, using analysis of variance, to determine differences among the groups with respect to intellectual and educational parameters. Secondly, patterns of performance in each of these domains were examined to identify any specific profiles which might discriminate among the groups. Thirdly, social and 


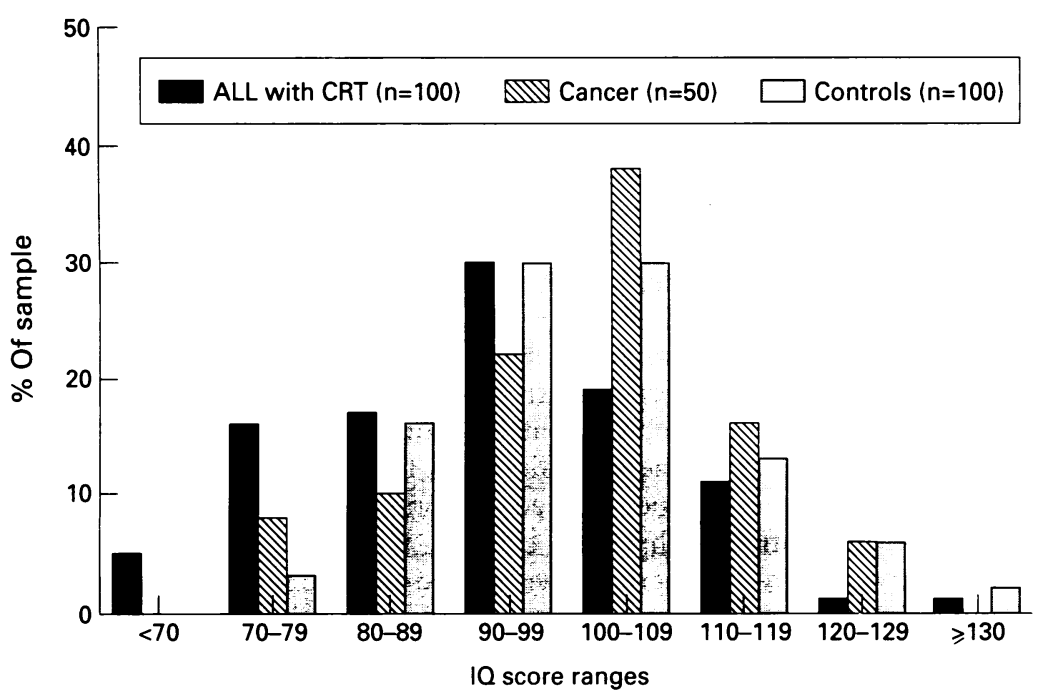

Figure 1 WISC-R verbal IQ distribution; $A L L=$ acute lymphoblastic leukaemia, $C R T=$ cranial irradiation.

behavioural profiles were contrasted for the two clinical groups.

\section{Results}

All children selected to participate in the study completed all intellectual and educational assessment tasks. Multivariate analysis of variance was used to investigate differences among the three groups. $T$ test results are reported for behavioural evaluations which have compared the two clinical groups.

\section{INTELLECTUAL ABILITIES}

The results showed that group 1 achieved significantly lower scores than groups 2 and 3

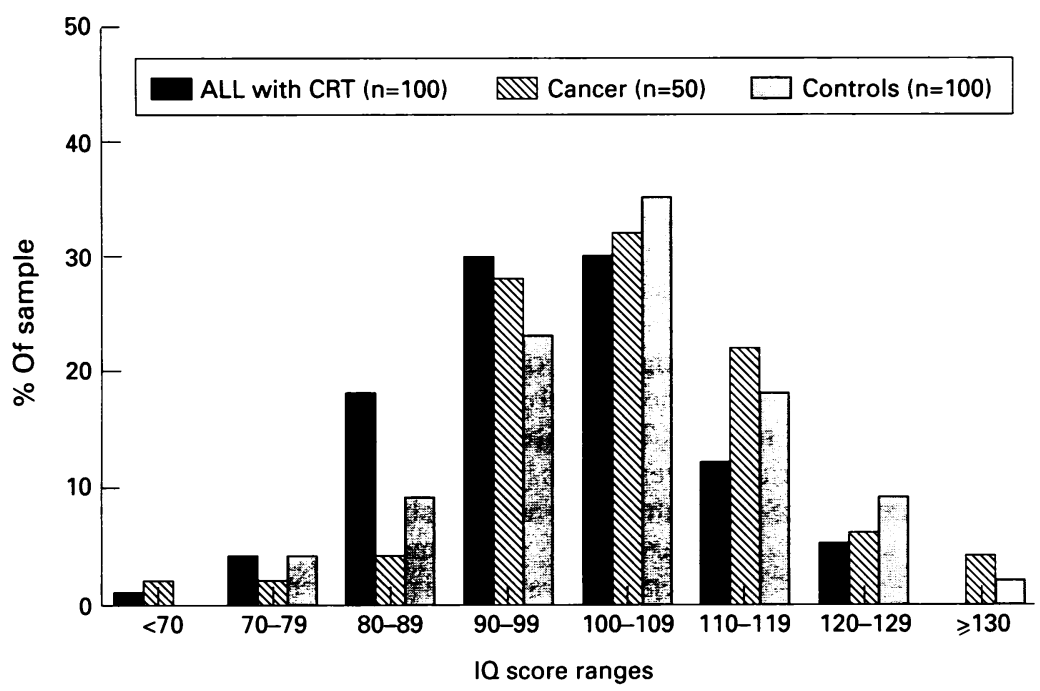

Figure 2 WISC-R performance IQ distribution; $A L L=$ acute lymphoblastic leukaemia, $C T R=$ cranial irradiation.

Table 3 Mean (SD) WRAT-R subtest scores for three comparison groups

\begin{tabular}{lllll}
\hline Subtest & $\begin{array}{l}\text { Group 1 } \\
\text { (CRT+chemotherapy) } \\
(n=100)\end{array}$ & $\begin{array}{l}\text { Group 2 } \\
\text { (chemotherapy only) } \\
(n=50)\end{array}$ & $\begin{array}{l}\text { Group 3 } \\
\text { (healthy controls) } \\
(n=100)\end{array}$ & $\begin{array}{l}F \\
\text { values }\end{array}$ \\
\hline Reading & $88 \cdot 0(18 \cdot 4)$ & $98 \cdot 1(18 \cdot 9)$ & $100 \cdot 5(14 \cdot 5)$ & $14 \cdot 3^{\star}$ \\
Spelling & $87 \cdot 8(16 \cdot 3)$ & $96 \cdot 8(15 \cdot 7)$ & $98 \cdot 5(13 \cdot 1)$ & $10^{\star}$ \\
Arithmetic & $88 \cdot 3(15 \cdot 1)$ & $98 \cdot 7(14 \cdot 5)$ & $96 \cdot 2(15 \cdot 6)$ & $10 \cdot 2 \dagger$ \\
\hline
\end{tabular}

CRT $=$ cranial irradiation

${ }^{\star} \mathrm{p}<0.0001 ; \mathrm{tp}<0.001$. on intellectual measures with both verbal IQ and performance IQ scores. Table 2 gives the intellectual quotients for each group and significance values.

Figures 1 and 2 give the distributions of scores for the three groups on intellectual measures. These figures indicate that the degree of intellectual deficit shown by children treated with cranial irradiation is relatively mild. The spread of intellectual quotients for both verbal and performance scales of the WISC-R are roughly equivalent for the three groups, but group 1, treated with cranial irradiation, records a lower mean score, with a higher frequency of children represented in the lower IQ ranges.

Inspection of the intellectual profiles of the three groups (table 2) further illustrates the inferior abilities of group 1, which records significantly lower mean scaled scores than the other groups on the following subtests of the WISC-R: information, similarities, vocabulary, arithmetic, and digit span for the verbal scale; and picture completion, block design, and coding for the performance scale.

\section{EDUCATIONAL ABILITIES}

Significant differences were also reported for all measures of academic achievement, with group 1 achieving the lowest scores for reading, spelling, and arithmetic subtests of the WRAT-R and group 2 performing similarly to healthy controls. Table 3 gives the test scores and significance values.

These results show that children receiving cranial irradiation and chemotherapy perform more poorly than children treated with chemotherapy alone or healthy controls, thus suggesting significant cognitive and educational sequelae associated with this treatment. Further, the scores achieved by those children treated with chemotherapy alone are similar to those of healthy controls, supporting the position that chemotherapy in isolation is not associated with educational or intellectual deficit.

SOCIAL COMPETENCE AND BEHAVIOURAL

STATUS

Table 4 gives the summary results from the Child Behaviour Checklist for groups 1 and 2 . Statistical analysis of these data found no differences between the two groups for $\mathrm{T}$ scores on the social competency scale $\left(t_{(136)}=0.84\right.$; $\mathrm{p}>0.05)$, although differences were detected for the school $\mathrm{T}$ scores $\left(\mathrm{t}_{(136)}=2.25 ; \mathrm{p}<0.05\right)$, with the cranially irradiated group recording poorer school performances based on parental ratings.

For the total behaviour scale, no differences were detected between the two clinical groups $\left(t_{(136)}=1.50 ; p>0.05\right)$. Further, no differences were detected for $\mathrm{T}$ scores on the internalising and externalising scales $\left(t_{(136)}=1.56\right.$; $\mathrm{p}>0.05 ; \quad\left(\mathrm{t}_{(136)}=0.31 ; \mathrm{p}>0.05\right.$ respectively $)$. Investigation of specific problem behaviour syndromes on this measure did detect differences between the groups, however, with 
Table 4 Social competency and behavioural characteristics of clinical groups. Values are mean (SD)

\begin{tabular}{lll}
\hline & $\begin{array}{l}\text { Group 1 } \\
\text { (CRT+ } \\
\text { chemotherapy) } \\
(n=100)\end{array}$ & $\begin{array}{l}\text { Group 2 } \\
\text { (chemotherapy } \\
\text { only) } \\
(n=100)\end{array}$ \\
\hline score & $45 \cdot 8(7 \cdot 9)$ & $46 \cdot 6(7 \cdot 5)$ \\
Activity score & $45 \cdot 2(8 \cdot 5)$ & $45 \cdot 6(7 \cdot 9)$ \\
Social score & $43 \cdot 0(8 \cdot 3)$ & $46 \cdot 0(6 \cdot 6)$ \\
School score & $44 \cdot 9(8 \cdot 2)$ & $46 \cdot 3(9 \cdot 0)$ \\
Social competency score & $50 \cdot 8(11 \cdot 9)$ & $47 \cdot 7(9 \cdot 6)$ \\
Total behaviour score & $53 \cdot 0(12 \cdot 0)$ & $49 \cdot 9(9 \cdot 4)$ \\
Internalising score & $47 \cdot 6(10 \cdot 9)$ & $47 \cdot 0(10 \cdot 4)$ \\
Externalising score & &
\end{tabular}

CRT $=$ cranial irradiation.

${ }^{\star} \mathrm{p}<0 \cdot 05$.

children treated with cranial irradiation recording scores most discrepant from normative expectations. Table 5 shows the mean scores for the two groups for each of the problem behaviour syndromes. Specifically, differences between the two groups were identified for the following syndromes: withdrawn $\left(\mathrm{t}_{(136)}=2 \cdot 10 ; \quad \mathrm{p}<0.05\right), \quad$ anxious/depressed $\left(\mathrm{t}_{(136)}=2.15 ; \mathrm{p}<0.05\right)$, social problems $\left(\mathrm{t}_{(136)}=\right.$ 2.58; $\mathrm{p}<0.01)$, and attention problems $\left(t_{(136)}=2.72 ; p<0.01\right)$. In each instance group 1 achieved higher mean scores, suggesting more problem behaviours.

\section{Discussion}

The results of this study support the hypothesis that children who receive cranial irradiation and chemotherapy for the treatment of acute lymphoblastic leukaemia have poorer intellectual and educational skills than children receiving chemotherapy alone or than healthy controls. Intellectual problems are generalised and refer to verbal and non-verbal skills, although there are greater discrepancies between the cranially irradiated group and non-irradiated groups for verbal abilities, with word knowledge, general knowledge, and abstract thinking being significantly poorer than for the other two groups. Further difficulties were detected on tasks tapping attentional or information processing skills.

The degree of intellectual deficit is relatively mild, with the mean intellectual quotients for both verbal and performance scales of the WISC-R for the cranially irradiated group being within the average range (that is, 90-109) as defined by Wechsler. ${ }^{43}$ The mild nature of the intellectual deficits recorded in this study may provide some explanation of the occurrence of

Table 5 Problem behaviour syndrome scores for the clinical groups. Values are mean (SD)

\begin{tabular}{|c|c|c|}
\hline$T$ score & $\begin{array}{l}\text { Group } 1 \\
\text { (CRT+ } \\
\text { chemotherapy) } \\
(n=100)\end{array}$ & $\begin{array}{l}\text { Group } 2 \\
\text { (chemotherapy } \\
\text { only) } \\
(n=100)\end{array}$ \\
\hline $\begin{array}{l}\text { Withdrawn }{ }^{\star} \\
\text { Somatic disorders } \\
\text { Anxious/depressed } \\
\text { Social problems } \dagger \\
\text { Thought problems } \\
\text { Attention problems } \dagger \\
\text { Delinquent behaviour } \\
\text { Aggressive behaviour } \\
\text { Sexual problems }\end{array}$ & $\begin{array}{l}55 \cdot 7(7 \cdot 6) \\
57 \cdot 2(8 \cdot 9) \\
55 \cdot 7(8 \cdot 4) \\
56 \cdot 1(9 \cdot 3) \\
53 \cdot 1(5 \cdot 3) \\
56 \cdot 1(8 \cdot 2) \\
53 \cdot 3(6 \cdot 1) \\
53 \cdot 4(6 \cdot 4) \\
52 \cdot 5(6 \cdot 1)\end{array}$ & $\begin{array}{l}53 \cdot 1(5 \cdot 2) \\
56 \cdot 0(6 \cdot 6) \\
53 \cdot 3(4 \cdot 8) \\
52 \cdot 4(4 \cdot 2) \\
53 \cdot 1(4 \cdot 8) \\
49 \cdot 9(9 \cdot 4) \\
54 \cdot 4(6 \cdot 3) \\
52 \cdot 5(4 \cdot 8) \\
51 \cdot 3(4 \cdot 6)\end{array}$ \\
\hline
\end{tabular}

CRT $=$ cranial irradiation.

${ }^{\star} p<0.05 ; \mathrm{tp}<0.01$. null results in previously published work, as many studies have used relatively small sample sizes which may not have had the statistical power to detect such subtle differences.

Educational difficulties are generalised for the cranially irradiated group. Reading, spelling, and mathematical abilities were all depressed, with the mean scores in each of these skill areas being outside the average range. ${ }^{44}$ Parent reports showed that 10 children treated with cranial irradiation had repeated at least one grade at school. Despite these difficulties few children received any specific educational support. In contrast, children treated with chemotherapy alone perform within the average range, and similarly to healthy controls, on educational measures, with only one child treated with chemotherapy alone reported to have repeated a grade. These findings indicate that factors such as school absenteeism and emotional responses to life threatening illness are insufficient to account for educational difficulties experienced by children with acute lymphoblastic leukaemia and treated with cranial irradiation.

The nature of intellectual and educational difficulties identified in this study are in contrast with those of many previous neuropsychological studies which suggest that non-verbal skills and arithmetical abilities are particularly vulnerable in children treated with cranial irradiation. ${ }^{151821}$ Instead, the current study detected the greatest discrepancies among the groups for tasks tapping language based skills and attentional abilities such as word knowledge, verbal reasoning, reading, and spelling. Measures of non-verbal ability such as visual planning, constructional abilities, and social comprehension were performed similarly by the three groups.

These findings are, however, consistent with a small number of studies 21946 which document linguistic and attentional problems in this population. Brouwers and Poplack ${ }^{22}$ argue that such problems in attention and linguistic skills are correlated with computed tomography results identifying calcifications of the basal ganglia bilaterally in their sample. Other workers ${ }^{4-49}$ have also shown this pattern of cognitive deficits in patients with damage to these cerebral regions.

The intellectual profiles and educational weaknesses identified after cranial irradiation coupled with chemotherapy have been described previously by Kaufman. ${ }^{50} \mathrm{He}$ reports a specific pattern of performance on the WISC-R, where mental arithmetic, short term memory, and psychomotor speed are depressed. He suggests that this profile is suggestive of attentional deficits which may interfere with the acquisition of educational skills.

Such a position reflects other research supporting the central role for linguistic and information processing skills in the acquisition of academic abilities. In particular, immediate memory, or the ability to register information from the environment, is seen to be especially relevant in the development of school learning difficulties. The reduced immediate memory 
or memory span detected in children treated with cranial irradiation (as measured by tasks such as the digit span subtest of the WISC-R) may act to reduce a child's ability to acquire information from the environment at the rate of their peers. As a consequence, the child may miss important information or perhaps misinterpret instructions. Further, such information processing difficulties may impede the development of specific skills such as phonic decoding and the retention of visual sequences which may limit progress in the areas of reading and spelling. ${ }^{51}$ The observed psychomotor speed and visuomotor incoordination difficulties (as measured by the coding subtest of the WISC-R) may be detrimental to school progress with children treated with cranial irradiation performing more slowly than their peers on tasks requiring written work.

Such linguistic and attentional deficits have often been related to socioeconomic status, which may have a substantial relation with educational and intellectual development. Although no particular social group has been recorded to be more at risk for experiencing acute lymphoblastic leukaemia, some studies have suggested that low socioeconomic status may place a child with an early neurological insult at greater risk of educational and intellectual problems. ${ }^{52} 53$ Careful control of this variable in this study suggests that socioeconomic status is not a sufficient explanation for differences detected in children treated with cranial irradiation and the two control groups.

Previous research has suggested that there may be a range of psychosocial causes for the intellectual and educational difficulties experienced by children treated with cranial irradiation. Emotional and psychosomatic symptoms $s^{34} 3554$ due to the experience of a life threatening illness, social difficulties, ${ }^{37} 39$ and absenteeism from school ${ }^{55} 56$ have all been advanced as possible explanations for these problems in this population. Such suggestions are not supported by this study. The finding that children treated with chemotherapy alone, who also have a life threatening illness and are absent from school for prolonged periods for treatment, perform similarly to control children argues that an alternative explanation is needed to account for the deficits shown by children treated with cranial irradiation and chemotherapy. Further, the consistency of mean age at diagnosis for the two clinical groups suggests that disruptions to schooling and other relevant developmental experiences should be similar between the two groups. For example, the percentage of children diagnosed within their kindergarten year or first year of school was similar, thus the difficulties associated with the acquisition of vital skills such as reading should have been experienced equally by the two clinical groups.

To further evaluate the importance of psychosocial factors, ratings of social competence and behaviour were obtained from the parents of the two clinical groups. As expected, given their equivalent life experiences, results from these measures suggested no overall differences in behavioural status for the groups. Scores for the two groups on the Child Behaviour Checklist fell within the average band, with no evidence of significant psychopathology. Investigation of specific aspects of social competence detected poorer scores for the cranially irradiated group on the school score, however, reflecting the parents' recognition of academic difficulties. Further, the children treated with cranial irradiation were observed by their parents to be more withdrawn and anxious, have poorer attention, and more social problems than children treated with chemotherapy only. Similar behavioural profiles have been previously recorded in learning disabled populations, ${ }^{5758}$ with workers suggesting that emotional and behavioural problems may be due to a combination of underlying neuropathology and experience of continuous school failure. Thus for children treated with cranial irradiation the attentional difficulties identified in the current sample may interfere with the acquisition of educational skills resulting in school failure. Secondary behavioural and emotional problems may then develop as a consequence of this failure and lead to socialisation difficulties, including withdrawal and social isolation.

The significant differences detected between children treated with cranial irradiation and non-irradiated children, then, are most likely to be associated with the specific treatment regimen and its effect on the developing central nervous system, rather than with environmental or social parameters. These findings support an interpretation which implicates cranial irradiation as a critical factor in the observed intellectual and educational problems detected in children with acute lymphoblastic leukaemia children treated with cranial irradiation and chemotherapy. Whether the observed deficits relate to cranial irradiation alone or in combination with chemotherapy is difficult to determine. Although some workers argue that a toxic synergism occurs when these two treatments are combined, ${ }^{59}$ the lack of separable neuropathological findings combined with the absence of deficits reported in patients after even very high doses of chemotherapy ${ }^{11}$ argues that the specific effects of cranial irradiation may be more significant to outcome.

These results raise a number of issues. Firstly, the magnitude of deficits reported in the current study suggest milder problems for childhood survivors of acute lymphoblastic leukaemia than do previous studies. This may be due to several factors including: (a) the more frequent use of lower dose radiation in this study distinguishes it from much previous research which has focused on children receiving 24 Gy cranial irradiation; (b) the neurological outcome of the group as a whole was better than that reported in previous work, with only 10 children in group 1 showing any form of neurological deficit; and (c) the sample included relatively fewer children radiated before the age of 5 than has been the case in previous studies.

Further, although children treated with cranial irradiation experience difficulties in the areas of language function and attentional 
capacity which may limit educational progress, they also show relative strengths, particularly in the areas of social reasoning and visuospatial and visual planning abilities. Using a neuropsychological strength approach ${ }^{60}$ to the task of helping these children develop educational skills suggests that interventions which capitalise on visual methods of teaching and individual tuition may compensate for weaker linguistic and attentional abilities.

\section{CONCLUSIONS}

This study has examined the premise that cranial irradiation treatment has long term and detrimental effects on the cognitive and educational abilities of childhood survivors of acute lymphoblastic leukaemia.

The results show that children diagnosed with acute lymphoblastic leukaemia and treated with cranial irradiation do experience problems in cognitive and educational abilities compared with healthy controls or to children treated with chemotherapy alone. Further, the poorer performances of these children cannot be explained by environmental or psychosocial factors (for example, socioeconomic status, school experience, emotional, or behavioural status) as these do not differ across the three comparison groups.

The current study has identified specific difficulties on tasks of attentional capacity (registration of information, psychomotor speed) and linguistic ability. These results are consistent with research which has implicated bilateral involvement of the basal ganglia in association with attentional and linguistic deficits.

Identified deficits after cranial irradiation are not severe, particularly for intellectual abilities, where many children treated with cranial irradiation function within the average range on psychometric tests. The more significant educational difficulties detected may be due to the specific nature of the identified cognitive difficulties - that is, linguistic and attentional problems. These difficulties may place children at risk for learning within the classroom environment. The relatively mild nature of the recorded difficulties, coupled with the presence of intact abilities in the areas of social reasoning and visuospatial abilities, indicate that these children may benefit from early educational intervention directed towards using cognitive strengths to compensate for difficulties in linguistic and attentional skills.

This research was supported by the Royal Children's Hospital Research Foundation, Melbourne, Australia and the AntiCancer Council of Victoria, Melbourne, Australia.

1 Sposto R, Hammond GD. Survival rates in childhood cancer. F Clin Oncol 1985; 4: 195-204.

2 Stehbens JA, Kaleita TA, Noll RB, et al. CNS prophylaxis of childhood leukemia: what are the long-term neurological, childhood leukemia: what are the long-term neurological, neuropsychological and behavio

3 Peckham V. Educational deficits in survivors of childhood cancer. Pediatrician 1991; 18: 25-31.

4 Price RA, Jamieson PA. The central nervous system in childhood leukemia: II. Subacute leukoencephalopathy. Cancer 1975; 35: 306-18

5 Tsuruda JS, Kortman KE, Bradley WG, Wheeler DC, Van Dalsem W, Bradley TP. Radiation effects on cerebral white matter, MR evaluation. Am f Neuroradiol 1987; 149: $165-71$.

6 Paakko E, Vainionpaa L, Lanning M, Laitinen J, Pyhtinen J.
White matter changes in children treated for acute lymphoblastic leukemia. Cancer 1992; 70: 2728-37.

7 Ochs JJ. Neurotoxicity due to central nervous system therapy for childhood leukemia. Am $\mathcal{F}$ Pediatr Hematol Oncol 1985; 11: 93-105.

8 Valk J, Van der Knaap MS. Toxic encephalopathy. $A m \mathcal{F}$ Neuroradiol 1992; 13: 747-60.

9 Ball W, Prenger EC, Ballard ET. Neurotoxicity of radio/ chemotherapy in children: pathologic and MR correlation. Ám $\mathcal{f}$ Neluroradiol 1992; 13: 761-76.

10 Tamaroff M, Miller DR, Murphy ML. Immediate and long-term posttherapy neuropsychologic performance in children with acute lymphoblastic leukemia treated without central nervous system radiation. F Pediatr 1982; 101: 524-9.

11 Fisk JL, Janakiraman N, O'Connell S. Cognitive functioning in patients treated with high dose chemotherapy. f Clin Exp Neuropsychol 1992; 14: 381 .

12 Eiser C. Effects of chronic illness on intellectual development. Arch Dis Child 1980; 55: 766-70.

13 Lansky SB, Cairns NU, Zwartjies W. Central nervous system prophylaxis: studies showing impairment in verbal skills and academic achievement. Am $\mathcal{F}$ Pediatr Hematol Oncol 1984; 6: 183-90.

14 Taylor HG, Albo VC, Phebus C, Sachs BR, Bierl PG. Post irradiation treatment outcomes for children with acute lymphocvtic leukemia. 7 Pediatr Psychol 1987; 12: 394-411.

15 Soni SS, Marten GW, Pitner SE, Duenas DA, Powazek M. Effects of central nervous system irradiation on europsychological functioning of children with acute lymphocytic leukemia. N Engl f Med 1975; 293: 113-8.

16 Ivnik RJ, Colligan RC, Obertz SW, Smithson WA. Neuropsychological performance among children in remission from acute lymphocytic leukemia. I Der Behaz Pediatr 1981; 2: 29-34.

17 Copeland DR, Dowell RE, Fletcher JM, Bordeaux D. Neuropsychological effects of childhood cancer treatment. 7 Child Neurol 1988; 3: 53-62.

18 Copeland DR, Fletcher JM, Pfefferbaum B, Jaffe N, Ried H, Maor M. Neurological sequelae of childhood cancer in $\mathrm{H}$, Maor M. Neurological sequelae of childhood can
long term survivors. Pediatrics 1985; 75: 745-53.

19 Cousens P, Ungerer JA, Crawford JA, Stevens M. Cognitive effects of childhood leukemia therapy: a case for four specific deficits. F Pediatr Psychol 1988; 16: 475-88.

20 Rogers J, Britton PG, Morris RG, Kernahan J, Craft A. Memory after treatment for acute lymphoblastic leukemia. Arch Dis Child 1992; 67: 266-8.

21 Fletcher JM, Copeland DR. Neurobehavioural effects of central nervous system prophylactic treatment of cancer in children. F Clin Exp Neuropsychol 1988; 10: 495-538.

22 Brouwers P, Polack D. Memory and learning sequelae in long-term survivors of acute lymphoblastic leukemia: long-term survivors of acute lymphoblastic leukemia: association with attention

23 Brouwers P, Riccardi R, Fedio R, Poplack D. Long-term neuropsychological sequelae of childhood leukemia: correlation with CT brain scan abnormalities. I Pediatr 1985; 106: 723-8

24 Marsden CD. The mysterious motor function of the basal ganglia. Neurology 1982; 32: 514-39.

25 Giralt J, Ortega JJ, Olive T, Verges R, Forio I, Salvador L. Long-term neuropsychologic sequelae of childhood leukemia: comparison of two CNS prophylactic regimens. Int $\mathcal{F}$ Radiat Oncol Biol Phys 1992; 24: 49-53.

26 Rowland JH, Glidewell OJ, Siblev RF, et al. Effects of different forms of central nervous system prophylaxis on neuropsychologic function in childhood leukemia. $f \mathrm{Clin}$ Oncol 1984; 2: 1327-35.

27 Hallberg FE, Kraemer JH, Moore IM, Wara W, Mattha K, Albin A. Prophylactic cranial irradiation dose effects on late cognitive function in children treated for acute lymphoblastic leukemia. Int 7 Radiat Oncol Biol Phys 1991; 22: 13-6.

28 Balsom WR, Blever WA, Robison LL, et al. Intellectual function in long term survivors of acute lymphoblastic leukemia: protective effect of pre-irradiation metholeukemia: protective effect of pre-irradiation methoPediatr Oncol 1991; 19: 486-92.

29 Mulhern RK, Wasserman AL, Fairclough D, Ochs J Memory function in disease free survivors of childhood acute lymphocytic leukemia given central nervous system prophylaxis with or without $1800 \mathrm{cGy}$ cranial irradiation. $\mathcal{F}$ Clin Oncol 1988; 6: 315-20.

30 Mulhern RK, Fairclough D, Ochs J. A prospective comparison of neuropsychologic performance of children surviving leukemia who received $18-\mathrm{Gy}$, or $24-\mathrm{Gy}$, or no cranial irradiation. f Clin Oncol 1991; 9: 1348-56.

31 Brown RT, Madan-Swain A. Cognitive, neuropsychological and academic sequelae in children with leukemia. Fournal of Learning Disabilities 1993; 26: 74-90.

32 Bluebond-Langner M. The private worlds of dying children. Princeton: Princeton University Press, 1978

33 Spinetta J, Deasy-Spinetta P, eds. Living with childhood cancer. St Dousy-Spinetta P,

34 Susman EJ, Hollenbeck AR, Nannis ED, et al. A prospective naturalistic study of an intensive medical treatment tive naturalistic study of an intensive medical treatment
on the social behaviour of child and adolescent cancer on the social behaviour of child and adolescent cancer
patients. fournal of Applied Developmental Psychology patients. Fournal

35 Kashani J, Hakami N. Depression in children and adolescents with malignancy. Can $\mathcal{F}$ Psychiatry 1982; 27: 474-7.

36 Greenberg HS, Kazak AE, Meadows AT. Psychologic functioning in 8 to 16 year old cancer survivors and their parents. I Pediatr 1989; 114: 488-93. 
37 Katz ER, Rubinstein CL, Hubert MC, et al. School and social reintegration of children with cancer. fournal of Psychosocial Oncology 1988; 6: 123-40.

38 Sawyer MG, Toogood I, Rice M, Haskell C, Baghurst P. School performance and psychological adjustment of children treated for leukaemia. Am $\mathcal{f}$ Pediatr Hematol Oncol 1988; 11: 146-52.

39 Noll RB, Bukowski WM, Rogosch FA, et al. Social interactions between children with cancer and their peers: teacher ratings. F Pediatr Psychol 1990; 15: 43-56.

40 Eiser C. Cognitive deficits in children treated for leukemia. Arch Dis Child 1991; 66: 164-8.

41 Cadman D, Boyle M, Szatmari P, et al. Chronic illness, disability and mental and social well-being: findings of the Ontario Child Health Study. Pediatrics 1987; 79: 805-13.

42 Ekert $\mathrm{H}$, Waters $\mathrm{KD}$, Matthews $\mathrm{RN}$, et al. A randomized study of corticosteroid and non-corticosteroid containing regimes in induction therapy of childhood ALL. Cancer Therapy and Control 1990; 1: 87-95.

43 Wechsler D. Wechsler intelligence scale for children - revised. San Antonio: The Psychological Corporation, 1974.

44 Jastak JS, Jastak S. The wide range achievement test. Wilmington: Jastak, 1984.

45 Achenback TM. Manual for the child behavior checklist/4-18 and 1991 profile. Burlington: University of Vermont, 1991 .

46 Brouwers, P, Riccardi R, Poplack D, Fedio P. Attentional deficits in long-term survivors of childhood acute lymphoblastic leukaemia (ALL). Fournal of Clinical Neuropsychology 1984; 6: 325-36.

47 Howes D, Boler F. Simple reaction time: evidence for focal impairment from lesions of the right hemisphere. Brain 1975; 98: 317-32.

48 Wallesch CW, Kornhuber HH, Brunner RJ, et al. Lesions of the basal ganglia, thalamus and deep white matter: differential effects on language functions. Brain Lang 1975; 20: $286-304$.

49 Metter EJ, Riege WH, Hanson WR, et al. Subcortical structures in aphasia: an analysis based on (f-18)fluorode-oxyglucose, positron emission tomography, and computed tomography. Arch Neurol 1988; 45: 1229-34.

50 Kaufman AS. Factor analysis of the WISC-R at eleven age levels between $6^{1} / 2$ and $16^{1 / 2}$ years. 7 Consult Clin Psychol 1975; 43: 135-47.

51 Anderson $V$. Why do intelligent children have learning difficulties? The neuropsychological perspective. $f$ Paediat Child Health 1992; 28: 278-80.

52 Taylor HG, Schatshneider C, Rich D. Sequelae of Haemophilus influenzae meningitis: implications for the study of brain disease and development. In: Tramontana MG, Hooper SR, eds. Advances in child neuropsychology. Vol 1. New York: Springer-Verlag, 1992.

53 Breslau N. Does brain dysfunction increase children's vulnerability to environmental stress. Arch Gen Psychiatry 1990; 47: 15-20.

54 Dolgin MJ, Katz ER, McGinty K, et al. Anticipatory nausea and vomitting in pediatric cancer patients. Pediatrics 1989 75: 547-52.

55 Stehbens JA, Kisker CT, Wilson BK. School behaviour and attendance during the first year of treatment for childhood cancer. Psychology in Schools 1983; 20: 23-8.

56 Lansky SB, Cairns NU, Zwartjes W. School attendance among children with cancer: a report from two centres. fournal of Psychosocial Oncology 1983; 1: 75-82.

57 Rourke B. The syndrome of non-verbal learning disabilities: developmental manifestations in neurological disease, disorder and dysfunction. Clin Neuropsychol 1988; 2: 293-30.

58 Spreen $O$. The relationship between learning disability, emotional disorders and neuropsychology: some results and observations. F Clin Exp Neuropsychol 1989; 11 $117-40$.

59 Gamis AS, Nesbit ME. Neuropsychologic (cognitive) disabilities in long-term survivors of childhood cancer. Pediatrician 1991; 18: 11-9.

60 Hartlage LC, Terzlow CF. The neuropsychological basis of educational intervention. Fournal of Learning Disabilities 1983; 16: 521-8.

61 Daniel A. Power, privilege and prestige: occupations in Australia. Melbourne: Longman-Cheshire, 1983. 